\title{
Laser Diode Pump Technology for Space Applications
}

\author{
Elisavet Troupaki, Mark A. Stephen, \\ Aleksey A. Vasilyev and Anthony W. Yu \\ NASA Goddard Space Flight Center, \\ USA
}

\section{Introduction}

In this chapter we will discuss the use of diode pump technology in space LIDAR (Light Detection and Ranging) missions. Space applications have a unique set of engineering requirements. In general, devices need to be reliable, compact, lightweight, efficient and rugged. Satellites need to survive launch and then operate in a vacuum, high-radiation, micro-gravity environment. Because of the high costs associated with launching payloads into space, lift capacity needs to be minimized and instruments need to be lightweight and compact. Because solar arrays and batteries that are necessary to operate powered equipment need to be launched as well, efficiency should be optimized to minimize the on-orbit power draw. Finally once an instrument has been launched into space, it is critical that it operates reliably - usually for several years. For the missions we will discuss in this paper, long-term reliable operation is very important to make comprehensive global measurements needed by the science community. In addition, these missions require customized science measurements, necessitating the design of one-of-akind instruments.

A major challenge is designing and building an instrument that is both unique and reliable.

To date, the space-based LIDAR instruments NASA has flown have been designed to make global (Earth, planetary and lunar) altimetry measurements. By making individual altimetry measurements as the satellite orbits a planet (or moon), the topography can be mapped. This measurement technique uses the time-of-flight of a laser pulse to travel from the spacecraft to the planetary surface and back to determine the distance between the source and target. This means there must be enough energy in the laser pulse to reach the planet and get sufficient return signal to measure the laser pulse. The systems engineering for these measurements is discussed elsewhere $[1,2,3,4,5]$ but for this type of measurement we used repetition rates in the 10's of $\mathrm{Hz}$ and pulse energies from a few to hundreds of milli-Joules (mJ). To build this type of laser we used quasi-continuous wave (QCW) laser diode arrays (LDAs) to pump an Nd:YAG laser crystal. Further details of the laser design are given in Section 2. To match the strong absorption in the Nd:YAG crystal, we chose $808 \mathrm{~nm}$ arrays. QCW LDAs are well suited for this application because they are 
efficient, compact and robust and are capable of delivering a high-power optical signal onto the laser crystal. They can also have both high spectral and spatial brightness. For these reasons, a QCW array has excellent performance characteristics and is very well suited to the space-flight application with one caveat: it does not have a well-defined lifetime or reliability. It is this aspect of the diode arrays that we will discuss in this chapter and although space-flight applications are a fairly narrow field, highly reliable operation is required in a broad range of applications and we believe this information is of general utility.

In the telecommunications industry, there is a large market that requires high volume production and supports device development and fabrication that adheres to telcordia requirements, ensuring repeatable, reliable performance. Unfortunately the diode-pumped solid-state laser (DPSSL) market does not have the same amount of investment and the market is much more disparate so there is less synergy around any one product or set of requirements. As a result, the available investments are spread among different devices and packaging schemes. In addition, the DPSSL market does not (in general) require multi-year reliability - bad parts can usually be serviced or replaced. The market is also very dynamic and requires continuous improvement so there is no set of frozen standards as exist in the telecommunications market. This means there is a continuous drive for increased performance so the devices are in a constant state of redesign. Gathering long-term data is not only not supported or required by the industry, in general, it does not make sense because the product whose reliability will be measured is obsolete by the time the data is gathered. So there is little effort to quantify the reliability or measure the lot-to-lot variability of these products.

None of this means the devices are of poor quality or that they do not perform well; on the contrary the devices perform very well, but the reliability of a given device is not well quantified.

So our challenge is to build a reliable laser based on parts that are not well understood. At NASA's Goddard Space Flight Center (GSFC) we have been evolving a process to get high performance, commercial-off-the-shelf (COTS) parts to meet our requirements for long-term space-flight operation.

A typical space flight mission consists of different phases

- $\quad$ Pre-Phase A, Conceptual Study

- Phase A, Preliminary Analysis

- $\quad$ Phase B, Definition

- $\quad$ Phase C/D, Design and Development

- $\quad$ Phase E, Operations Phase

Formal reviews are typically used as control gates at critical points in the full system life cycle to determine whether the system development process should continue from one phase to the next, or what modifications may be required. Only key reviews at various phases of the mission development are shown in Table 1. In the last column, we listed the development phases of the instrument coinciding with various mission reviews. We will briefly describe the space qualification process of a particular component. 


\begin{tabular}{|c|c|c|}
\hline Mission Phase & $\begin{array}{l}\text { Mission Reviews and } \\
\text { Operations }\end{array}$ & Instrument Development \\
\hline $\begin{array}{l}\text { Pre-Phase A } \\
\text { Conceptual Study }\end{array}$ & $\begin{array}{l}\text { - MISSION CONCEPT } \\
\text { REVIEW (MCR) }\end{array}$ & $\begin{array}{l}\text { - Conceive Concept and Conduct Trade } \\
\text { Studies }\end{array}$ \\
\hline $\begin{array}{l}\text { Phase } \mathbf{A} \\
\text { Preliminary Analysis }\end{array}$ & $\begin{array}{l}\text { - SYSTEM } \\
\text { REQUIREMENTS REVIEW } \\
\text { (SRR) } \\
\text { - SYSTEM DESIGN } \\
\text { REVIEW (SDR) } \\
\text { - NON-ADVOCATE REVIEW }\end{array}$ & $\begin{array}{l}\text { - Preliminary Design } \\
\text { - Proof of concept Breadboard }\end{array}$ \\
\hline $\begin{array}{l}\text { Phase B } \\
\text { Definition }\end{array}$ & $\begin{array}{l}\text { - PRELIMINARY DESIGN } \\
\text { REVIEW (PDR) }\end{array}$ & $\begin{array}{l}\text { Define baseline technical solution } \\
\text { - Define requirements } \\
\text { - Procure parts to begin qualification process } \\
\text { - Build Engineering Model (EM) }\end{array}$ \\
\hline $\begin{array}{l}\text { Phase C/D } \\
\text { Design } \\
\& \\
\text { Development }\end{array}$ & $\begin{array}{l}\text { - } \text { CRITICAL DESIGN } \\
\text { REVIEW (CDR) } \\
\text { - TEST READINESS } \\
\text { REVIEW } \\
\text { - FLIGHT READINESS } \\
\text { REVIEW }\end{array}$ & $\begin{array}{l}\text { - Freeze design } \\
\text { Procure flight and spare parts } \\
\text { - Build Flight and Flight Spare System } \\
\text { Environmental Testing } \\
\text { - Deliver Flight and Flight Spare } \\
\text { Integrate with Spacecraft }\end{array}$ \\
\hline $\begin{array}{l}\text { Operations Phase } \\
\text { Mission Ops } \\
\& \\
\text { Data Analysis }\end{array}$ & $\begin{array}{l}\text { - PRIMARY MISSION } \\
\text { - EXTENDED MISSION }\end{array}$ & \\
\hline
\end{tabular}

Table 1. Full mission cycle with critical reviews within the cycle and corresponding development phase of the instrument.

Well-defined and proven manufacturing processes producing reliable components from space-qualified vendors are key to a successful mission. Previously flown missions provide references to baseline components, which include EEE, optical, photonics and optoelectronics parts for upcoming missions with lessons learned. In practice, these previously flown parts are often obsolete or have enough modification in either the manufacturing process or ingredients that these references can only be used as guidelines. During the Phase A, the proof-of-concept breadboard is being built, components will be chosen with future qualification in mind. Components that were flown previously will have first priority due to heritage along with other qualifiable alternate choices. During this breadboard phase, samples from potential vendors will be purchased and their performances characterized. This information will then be used to select vendors and parts for the engineering model (EM) development in Phase B. Another approach to mitigate risk on key components is to choose multiple vendors for the flight to guard against the risk of manufacturing flaw in the flight lot from a particular vendor. Sometimes, but not often due to schedule constraints, multiple rounds of purchase and test would be conducted before the components are integrated into the instrument. This is typically done within Phase B of the program.

Procurement of flight parts typically occurs at the end of Critical Design Review (CDR). Exception may apply for long lead items such as pump diodes where procurement usually starts after completion of the Preliminary Design Review (PDR). When procuring flight parts, typical practice is to procure a large enough quantity for building the flight, flight spares and additional parts for quantifying the performance through various tests described below. 
Upon receiving the flight parts, the performances of the components are characterized to understand how they operate and the part-to-part variability in their performances. Our strategy is to purchase enough quantities to characterize the lot-to-lot variability and obtain insights into the overall instrument performance range with these variances. Extensive optical characterization and other measurements will be described in Section 3.

In addition to measuring the optical characteristics of the device, we also have a suite of high-fidelity tests that are designed to detect characteristics of the device like mechanical stress, manufacturing errors or device damage. These methods can be used to screen the flight devices so that only the best devices are selected for integration onto the satellite.

Once the as-delivered characteristics of the devices are well characterized, we then subject them to a battery of environmental and operational tests to quantify how they will operate in our system. These include life tests, vibration, simulated thermal stresses and vacuum. Again we look for the mean performance as well as the variability so that the on-orbit performance can be adequately predicted. These test procedures and sample results will also be presented in Section 3.

Where possible, we perform accelerated life-tests and derive the acceleration parameters from the collected data. Understanding accelerated lifetest results is extremely difficult and relies heavily on a good design of experiment. Actual lifetime data in the as-used conditions is important even if it means taking data for a long period of time. Where there is uncertainty in results, it is important to be conservative in the conclusions that can be drawn. Once the results of the tests are available, correlating lifetest and environmental data to the screening criteria should be done where possible to validate the methodology.

\section{Current NASA space LIDAR missions employing QCW LDAs}

There are currently three operational LIDAR systems developed by NASA orbiting the Earth, the Moon and the planet Mercury gathering scientific data to form a better understanding of our Earth and solar system. All these LIDAR systems were built using high power QCW LDA pumped solid-state laser (SSL) architectures. These QCW LDA pumped SSL laser systems are the enabling technology that led to a series of successful spaceflight LIDAR systems for Earth observing and planetary exploration. One of the first DPSSL was the Mars Orbiter Laser Altimeter (MOLA) laser transmitter launched in 1996, which produced a high resolution topographic map of the planet Mars. [6] This was followed by the Geoscience Laser Altimeter System (GLAS) in 2003. Three LIDAR systems currently in operation also use this architecture: the Cloud-Aerosol Lidar with Orthogonal Polarization (CALIOP) launched in 2006, the Mercury Laser Altimeter (MLA) launched in 2006; and the Lunar Orbiter Laser Altimeter (LOLA) launched in 2008. [7,8,9,10] These USled LIDAR instruments as well as missions from other countries have produced vast amounts of valuable scientific data for the study of our solar system.

QCW LDA pumped Nd:YAG lasers have been used since the late 1990's in all of the spaceborne LIDAR missions for NASA. The MOLA instrument was launched on the Mars Global Surveyor (MGS) in 1996. The MOLA laser was a diode-pumped, Nd:YAG zigzag slab, cross-Porro, electro-optically q-switched laser transmitter. It operated at $1.064 \mu \mathrm{m}$ wavelength with a pulse energy of $40 \mathrm{~mJ}$, pulse width of $10 \mathrm{~ns}$ and repetition rate of $10 \mathrm{~Hz}$. The prime science objective of MOLA was to determine the global topography of Mars at a level suitable for addressing problems in geology and geophysics. Since the launch of MGS 
in November 1996 until the instrument was commanded off on June 2001, a total of 670 million shots were fired with 640 million measurements of the Mars surface and atmosphere. This represents more than ten times the number of laser measurements than all previous space LIDAR missions combined. The MOLA instrument performance and lifetime surpassed all goals of the MOLA investigation. [11] The Shuttle Laser Altimeter (SLA) I \& II flew a copy of the MOLA laser in 1996 and 1997 to produce topographic profiles of the Earth surface and accumulated a total of about 6 million shots in space. [12]

The GLAS laser transmitter is the first passively q-switched, master oscillator power amplifier (MOPA) design that has operated in space. The instrument was launched in 2003 and completed its mission in early 2011 with a total of just under 2 billion shots in space from three transmitters. [13] The GLAS lasers represent a substantial improvement in performance over previous space-based remote sensing laser transmitters. The GLAS lasers simultaneously increased performance in power $(110 \mathrm{~mJ}$ total with $75 \mathrm{~mJ}$ at $1.06 \mu \mathrm{m}$ and 35 $\mathrm{mJ}$ in $0.532 \mu \mathrm{m})$, full beam divergence $(110 \mu \mathrm{rad})$, pulse width $(<6 \mathrm{~ns})$, single spatial mode with $\mathrm{M}^{2} \sim 2$ and repetition rate $(40 \mathrm{~Hz})$. The GLAS MOPA's modular laser design also provided the baseline architecture for the next two missions; to the planet Mercury and the Moon.

The Mercury Surface, Space Environment, Geochemistry, and Ranging (MESSENGER) mission to the planet Mercury requires a laser altimeter capable of performing range measurements to the surface of the planet over highly variable distances and with a constantly changing thermal environment. The satellite reached final orbit after more than 5 years of transit through space and began gathering data in March 2011. It is in a highly elliptical orbit with a periapsis of $200 \mathrm{~km}$, an apoapsis of approximately 15,200 km and an orbital period of $12 \mathrm{~h}$. For the altimeter instrument, science observations are taken during the $0.5 \mathrm{~h}$ of closest approach to the planet. The laser must support the instrument requirement of a range resolution of less than $40 \mathrm{~cm}$ to the surface of the planet. The anticipated radiation exposure over the mission life is $30 \mathrm{krad}(\mathrm{Si})$, total dose, using an effective shielding of $0.1 \mathrm{~cm}$ of aluminum. During the close approach to the day side of the planet, the satellite is heating and it is not possible to fully isolate the laser subsystem from the rest of the satellite. Mission requirements on the laser include more than $18 \mathrm{~mJ}$ of output energy in a near-diffraction-limited beam with 6 ns pulses at an $8 \mathrm{~Hz}$ repetition rate, while the laser bench temperature is executing a thermal ramp from 15 to $25^{\circ} \mathrm{C}$ at a rate of approximately $0.4^{\circ} \mathrm{C} / \mathrm{min}$. The MLA laser transmitter was based on the GLAS MOPA laser design but with only a single amplifier stage. The oscillator was changed from a Porro/Mirror resonator to a cross-Porro resonator to ensure that the laser will maintain its alignment over the harsh environment of Mercury.[4]

The first spaceflight LIDAR, coming just ten years after the demonstration of the first laser in 1960, was flown on Apollo 15, then subsequently on Apollo 16 and 17, provided the first topographic mapping of the Moon from orbit. It was a flash lamp pumped, mechanically qswitched ruby laser built by RCA. [14] The Lunar Reconnaissance Orbiter (LRO) marked our return to the moon after more than four decades since the Apollo era with the objectives to conduct scientific investigations and prepare for future human exploration of the Moon, Mars and beyond. The overall mission objective for LRO is to find and locate landing sites, identify potential resources, characterize the radiation environment and demonstrate new technology. LRO was launched in 2009 and has completed the exploration phase of the mission, which lasted for 1-year after first turn-on. The mission is now in its science phase. The LOLA instrument is the first multi-beam altimeter system in space; a diffractive optical 
element (DOE) at the exit aperture of the transmit telescope produces five beams that illuminated the lunar surface. For each beam LOLA measures time of flight (range), pulse spreading (surface roughness), and transmit/return energy (surface reflectance). With its two-dimensional spot pattern, LOLA unambiguously determines slopes along and across the orbit track. Analysis of the data at cross-over points from multiple orbital tracks will also provide insight on the gravitational field of the moon and its center of mass. The LOLA laser transmitter, using only a modified master oscillator from the GLAS modular design, is a diode pumped, Cr:Nd:YAG slab with passive q-switch and a cross-Porro resonator configuration. The laser transmitter consists of a beryllium (Be) flight laser bench housing two oscillators (a primary oscillator and a cold spare), an 18X transmit beam expander and a DOE. [15]

\section{Space qualification process at NASA's goddard space flight center}

As already mentioned, there are currently no universal military or NASA standards to follow in order to space-qualify the laser diodes that are used to pump spaceborne lasers.

Over the last decade, our group at GSFC has been working to quantify the reliability of COTS parts and address any issues with their operation in space. Our work has focused primarily on the $808 \mathrm{~nm}$ QCW diode stacks.

Characterizations of samples and flight parts, long-term tests and familiarity with the market and diode technology have helped us identify and use quality products. Our practice has been to design a diode qualification and screening process based on the operating conditions and requirements of each mission, the acceptable risks as well as the available time and budget. We present an illustrative example of such a process in Section 4 . Table 2 summarizes the types of pump diodes used in recent missions, their requirements and operating conditions such as pump pulse width, pulse repetition rate (PRF) and operating current:

\begin{tabular}{|c|c|c|c|}
\hline $\begin{array}{l}\text { MISSION- } \\
\text { DURATION }\end{array}$ & Instrument & $\begin{array}{c}\text { Number of diode } \\
\text { bars / wavelength / } \\
\text { type }\end{array}$ & $\begin{array}{c}\text { ENVIRONMENT/ } \\
\text { OPERATING CONDITIONS } \\
\text { (Pump Pulsewidth, PRF, } \\
\text { Nominal Operating) }\end{array}$ \\
\hline $\begin{array}{c}\text { MGS } \\
1996-2001\end{array}$ & MOLA & $\begin{array}{l}44 / 808 \mathrm{~nm} / \\
\text { diode stack }\end{array}$ & $\begin{array}{c}\text { Vacuum } \\
150 \mu \mathrm{s}, 10 \mathrm{~Hz}, 60 \mathrm{~A}\end{array}$ \\
\hline $\begin{array}{c}\text { ICESat } \\
2003-2010\end{array}$ & GLAS & $\begin{array}{l}54 / 808 \mathrm{~nm} / \\
\text { diode stack }\end{array}$ & $\begin{array}{c}\text { Vacuum } \\
200 \mu \mathrm{s}, 40 \mathrm{~Hz}, 100 \mathrm{~A}\end{array}$ \\
\hline $\begin{array}{c}\text { CALIPSO } \\
2006-\text { present }\end{array}$ & CALIOP & $\begin{array}{l}\text { 192/808nm/ } \\
\text { diode stack }\end{array}$ & $\begin{array}{c}\text { Pressurized } \\
150 \mu \mathrm{s}, 20 \mathrm{~Hz}, 60 \mathrm{~A}\end{array}$ \\
\hline $\begin{array}{l}\text { MESSENGER } \\
2006 \text { - present }\end{array}$ & MLA & $\begin{array}{l}\text { 10/808nm/ } \\
\text { diode stack }\end{array}$ & $\begin{array}{c}\text { Vacuum } \\
160 \mu \mathrm{s}, 8 \mathrm{~Hz}, 100 \mathrm{~A}\end{array}$ \\
\hline $\begin{array}{c}\text { LRO } \\
2008 \text { - present }\end{array}$ & LOLA & $\begin{array}{l}\text { 2/808nm/ } \\
\text { diode stack }\end{array}$ & $\begin{array}{c}\text { Vacuum } \\
200 \mu \mathrm{s}, 28 \mathrm{~Hz}, 90 \mathrm{~A}\end{array}$ \\
\hline $\begin{array}{c}\text { ICESat2 } \\
2016 \text { launch }\end{array}$ & ATLAS & $\begin{array}{l}\text { NA/880nm/fiber- } \\
\text { coupled }\end{array}$ & $\begin{array}{c}\text { Pressurized } \\
\text { CW, - TBD }\end{array}$ \\
\hline
\end{tabular}

Table 2. Summary of flown types of diode pumps, their requirements and operating conditions 
Since 2003, the laser diode group at GSFC has developed the necessary infrastructure and has an on-going program for LDA characterization and long-term testing in air and in vacuum environments. The data collected is used to compare and rank the LDAs. Only LDAs satisfying certain criteria, usually established by the mission requirements, are selected for use in space.

After receiving an LDA from a vendor, we mount it on a specially designed test plate, which can be mounted on all necessary test stations and thus minimize handling of the device and the risk of electro-static discharge (ESD) events (Fig. 1). Then the LDA is characterized. Fig. 2 shows a schematic of the characterization set-up.

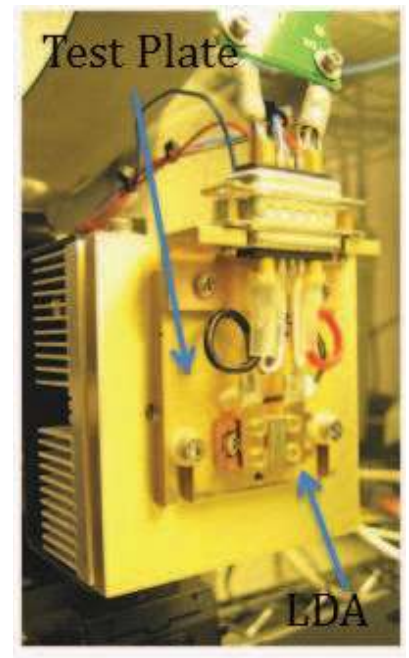

Fig. 1. LDA on a test plate mounted on the performance test station.

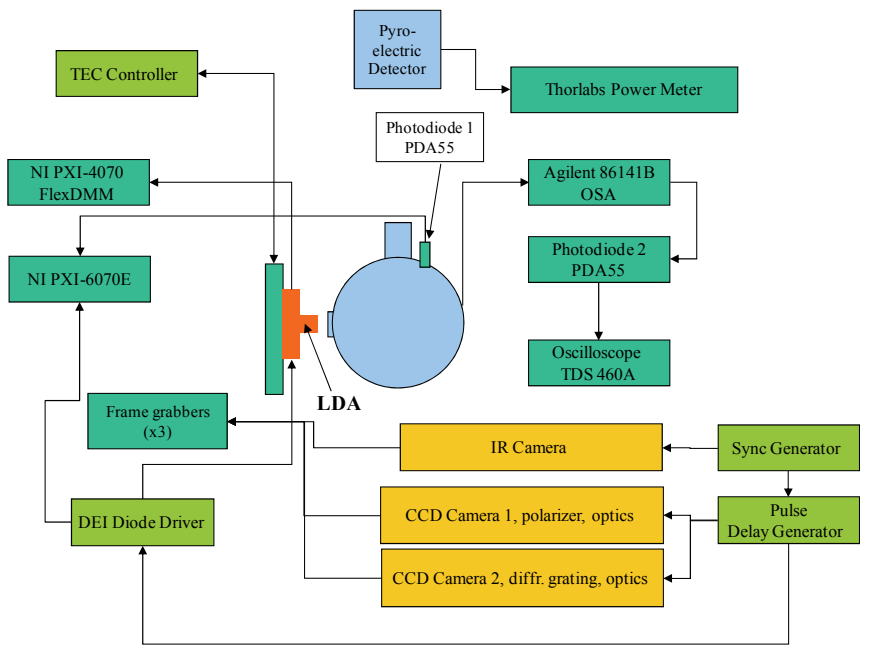

Fig. 2. Schematic of the LDA characterization set-up. 
Each standard LDA characterization consists of the following steps:

1. Microscope inspection of the diode bars' facet and side - To reveal defects introduced during manufacturing such as minor cracks, solder material on the emitting area, impurities on the diode facet, discoloration and coating defects (see examples in Fig. 3).
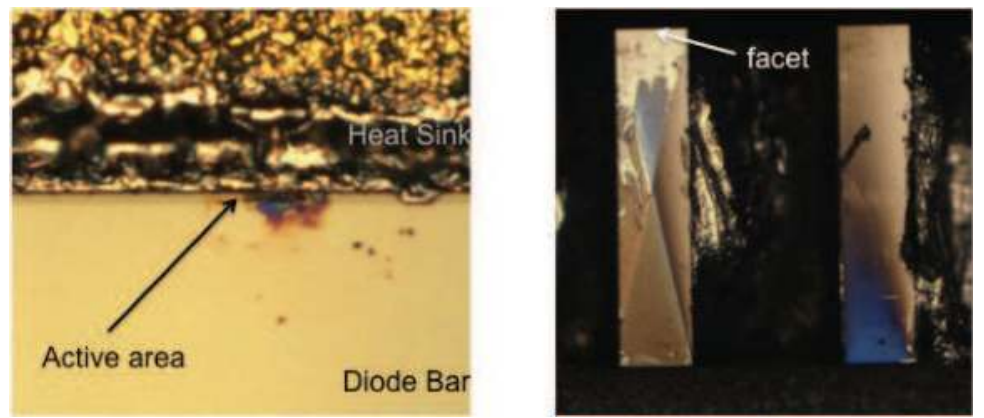

Fig. 3. Samples of high-magnification imaging of the bar facet (left) and side (right).

2. IR bar facet thermography - To reveal any hot spots. Temperature stresses may affect device lifetime by generating or accelerating the formation of defects. [16,17] Fig. 4 shows a sample of an IR thermographic image of a two-bar LDA facet operating at $100 \mathrm{~A}, 0.6 \%$ duty cycle. The image shows the temperature difference between the LDA when it is powered on and off. The temperature profile is attained by subtracting the IR image of the LDA which is off (background image) from the image when the LDA is on.

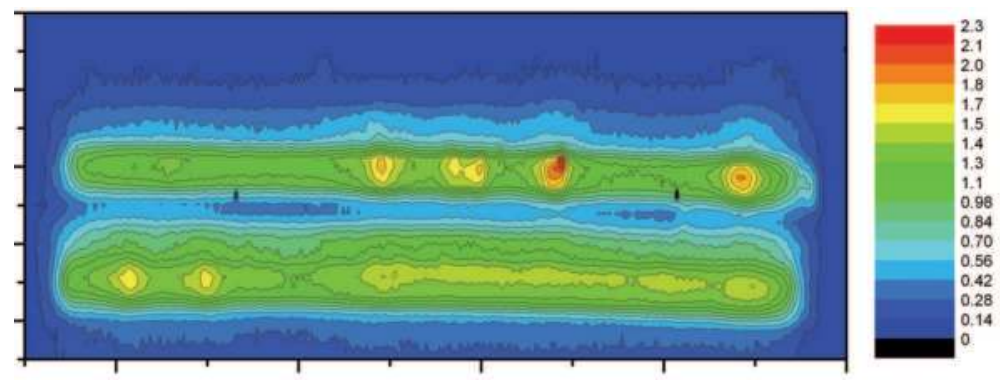

Fig. 4. IR facet thermographic image of a two-bar LDA operated at 100A. In this example, the hot spots have temperatures approximately twice the average bar temperature.

3. Near Field (NF) imaging - To determine if there are any dead emitters (Fig. 5).

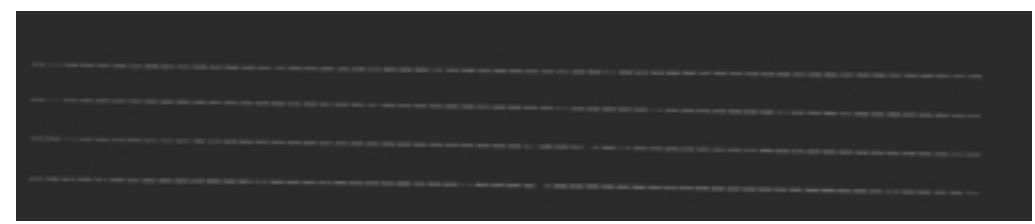

Fig. 5. Near Field imaging of a 4-bar LDA operating at 100A, $0.6 \%$ duty cycle can reveal dead emitters. 
4. Polarization ratio measurements - Internal defects and stress in the active region of the diode laser can be revealed by a small de-polarization of the output light. [18,19] For that reason, we filter the optical output with a polarizer set to either $0^{\circ}$ or $90^{\circ}$ with respect to the diode junction plane to capture polarization-resolved near field images. We place the polarizer behind the Neutral Density (ND) filters to prevent polarizer damage or over heating by radiation. To further reduce the heat load on the polarizer, the LDA is triggered at $1 \mathrm{~Hz}$. A sample of the profile of the LDA output for TE and TM modes at 100A is shown in Fig. 6. The pink line shows the relative power polarized in the TE mode (parallel to the slow axis of the emitters) across the diode bar and the blue line shows the relative power polarized in the TM mode. Because the light is preferentially polarized in the TM mode, the TE mode line is scaled up approximately 200 times. The normal de-polarization ripples represented by the weak TE mode output and shown along the bar are correlated with the $\mathrm{V}$-grooves that separate the emitters. A more pronounced de-polarization peak is visible in the center of the bar. The measurements of the degree of polarization well below the LDA threshold current of $12 \mathrm{~A}-14 \mathrm{~A}$ can also be used to detect laser bar stress. [20,21]

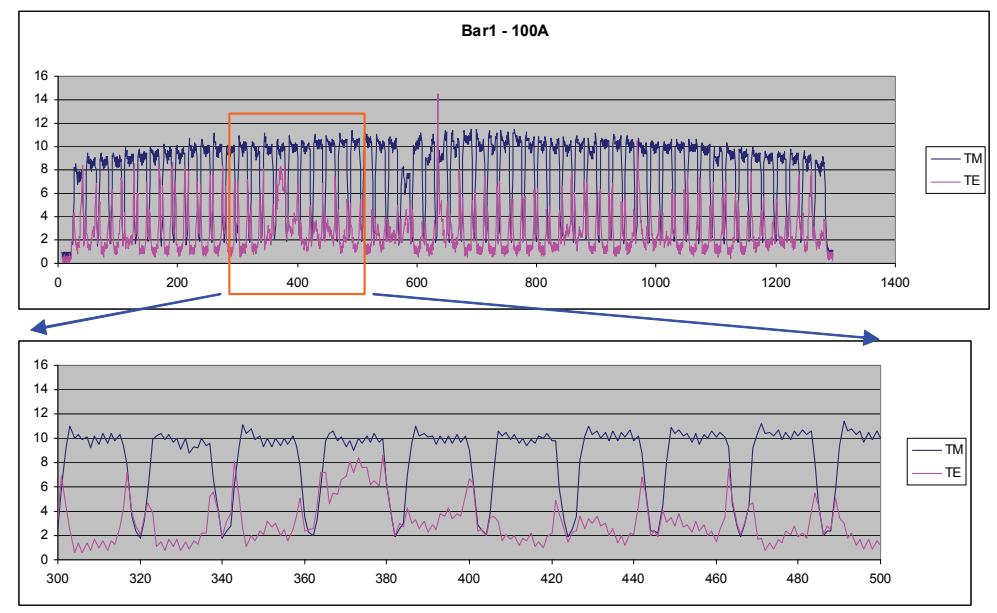

Fig. 6. Intensity profile of an LDA optical output at 100A for TE and TM polarization modes. We filter the optical output with a polarizer set to either $0^{\circ}$ or $90^{\circ}$ with respect to the diode junction plane to capture polarization resolved near field images. We are using a polarizer with an extinction ratio greater than 10,000 in our wavelength range. The optical signal is attenuated with ND filters to avoid saturating the CCD sensor. We place a polarizer behind ND filters to prevent polarizer damage or over heating by LDA output radiation. To further reduce the heat load on the polarizer, the LDA was triggered at $1 \mathrm{~Hz}$.

\section{NF spectrographic imaging}

To identify peaks in the wavelength spatial profile of the diode bar. Spatially resolved bar spectra are acquired by an imaging spectrometer (Fig. 7). The spectrometer has a diffraction grating of 1200 lines/mm and the resolution is better than $0.1 \mathrm{~nm}$. The spectrum is captured by a monochrome CCD camera. A spatially resolved spectrum of the laser diode array bar is shown in Fig. 8. 


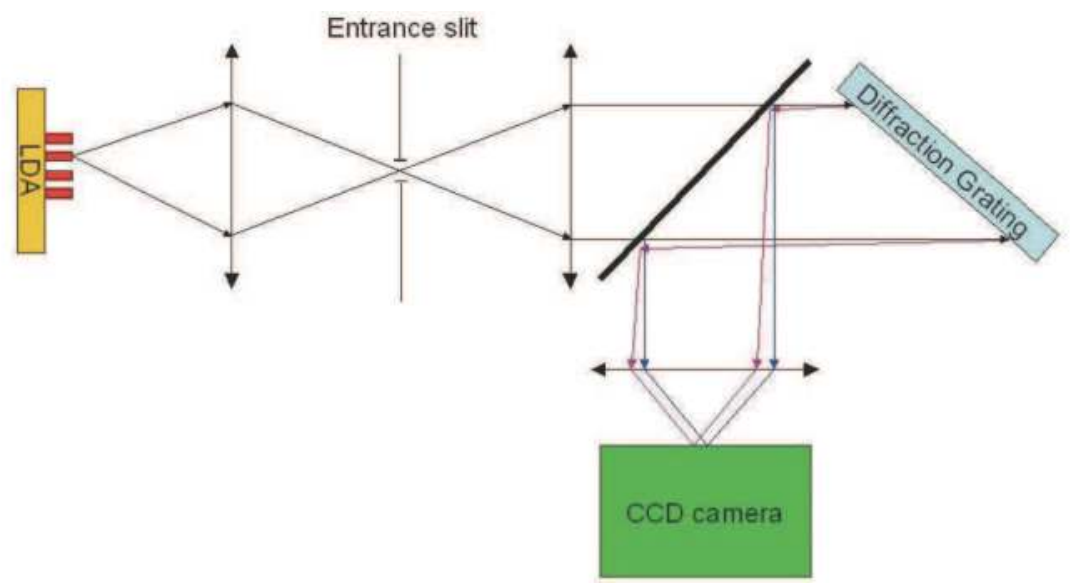

Fig. 7. The diagram of imaging spectrometer. The spectrometer has a diffraction grating of 1200 lines/mm working in the auto collimation regime. The spectrometer dispersion is equal to $4.3 \times 10^{-6}$ and resolution is better than $0.1 \mathrm{~nm}$. The spectrum is captured by a monochrome 1.4Mpixel CCD camera.

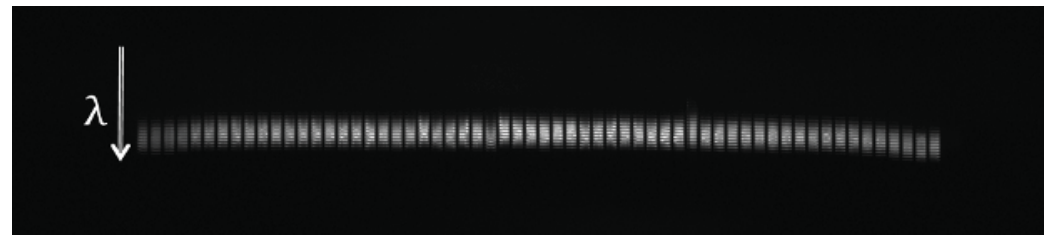

Fig. 8. An example of an acceptable spectrographic image of a diode bar operated at 20A, $0.6 \%$ duty cycle.

Each light feature in Fig. 8 corresponds to the intensity of the light emitted by an element; however the vertical distribution indicates the wavelength dispersion. The wavelength increases in the vertical direction of the arrow. The spectrum is taken at 20A current.

In a recent case, the emission wavelength appeared to have a wavy pattern along the bar (Fig. 9). The periodic change of the emission wavelength indicated residual mechanical stress. We worked closely with the vendor who quickly identified and resolved the issue by improving the bar mounting process. The spectrographic images of the new LDAs then looked similar to the one in Fig. 8.

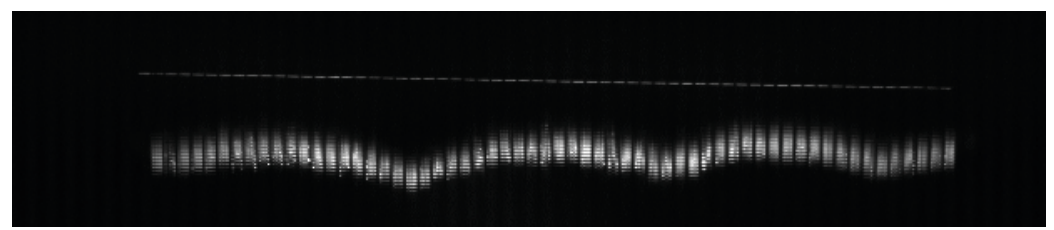

Fig. 9. A "wavy" spectrographic image of a diode bar, measured at 20A, $0.6 \%$ duty cycle, indicates residual mechanical stress. 


\section{Current and voltage measurements}

We measure current supplied by diode driver and voltage across the laser diode array. These measurements are necessary to calculate the threshold current, slope efficiency, diode array serial resistance, and wall plug efficiency. The LDA threshold current and slope efficiency are derived from optical power vs. current measurement (P-I curve, as in Fig. 10 (left)), LDA serial resistance from voltage vs. current measurement, and LDA efficiency from the previous two. We assess the efficiency of the LDA and observe whether there is any roll-over on the P-I curves, which may suggest thermal issues on the package.

\section{Average spectral measurements}

We typically measure LDA average spectrum at three different currents (Fig. 10 (right)) to get a baseline measurement of the center wavelength and wavelength distribution. We have seen evidence of spectra on a few devices that change shape as the current is increased which is generally a signal that there is uneven heating in the array.
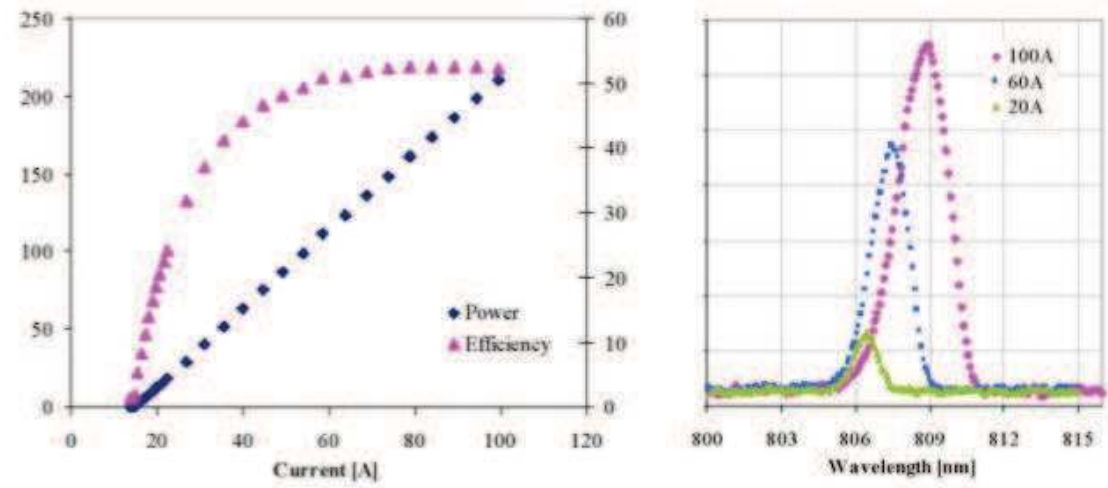

Fig. 10. Samples of P-I and efficiency curves (left) and spectral measurements at three different currents (right). [22]

8. Temporally and Spectrally Resolved (TSR) measurement at maximum current

A measurement of the temperature of the active region is an important parameter as the lifetime of LDAs decreases with increasing temperature. [17] We measure the temperature from time-resolving the spectral emission in an analogous method to Voss et al. [23]. Time-resolved spatially averaged emission measurements are made with an optical spectrum analyzer set to "filter-mode", a photodiode fiber-coupled with an integrating sphere and a digital oscilloscope as shown in Fig. 2. In filter-mode the OSA acts as a narrow optical band-pass filter. The center of the filter is stepped through the emission spectrum of the LDA. For each wavelength, the intensity vs. time profile is recorded via the digitizing oscilloscope. The resulting data matrix is then analyzed to determine the peak wavelength as a function of time. The temporally resolved spectra show a temperature induced chirp to longer wavelengths. This chirp is attributed to the current pulse thermally tuning the device. We calculate the thermal rise of the LDA using the typical wavelength shift value of $\sim 0.3 \mathrm{~nm} /{ }^{\circ} \mathrm{C}$. The peak wavelength, full-width at half-maximum (FWHM) and temperature derived from the temporally resolved data matrix are plotted in Fig. 11. 


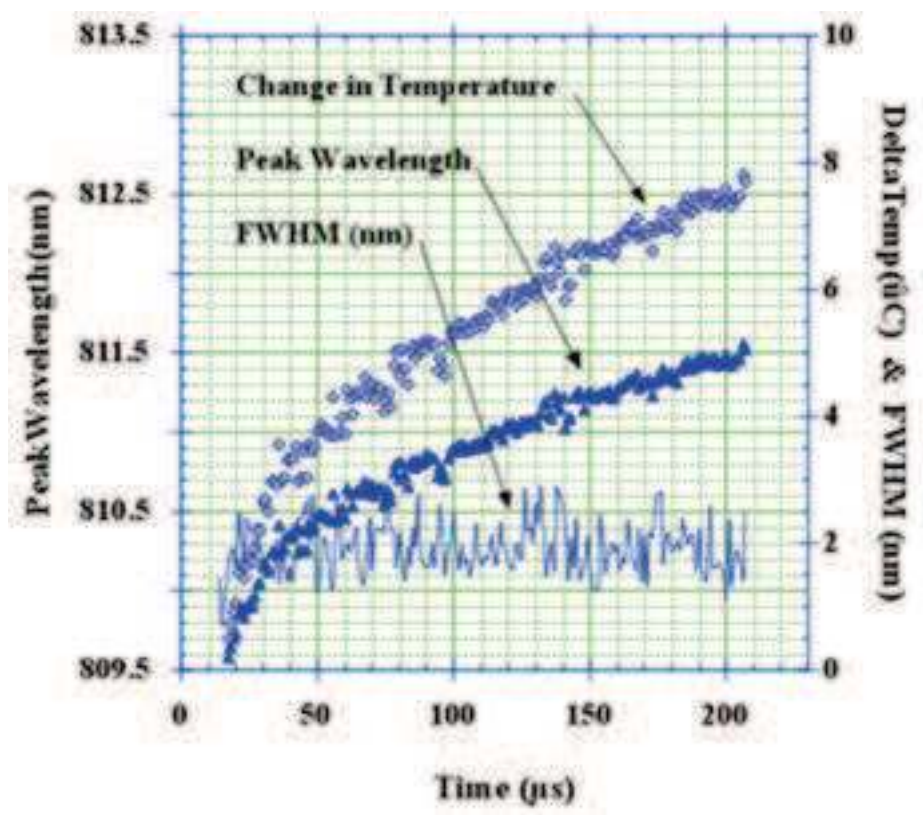

Fig. 11. Change in peak wavelength, full-width at half-maximum and temperature as a function of time at 100A, during a current pulse of $200 \mu \mathrm{s}$, derived from the temporally resolved data matrix. [22]

Packaging-induced stress and defects have been found to play a significant role in LDA reliability and therefore their early detection is critical for device screening and space qualification. There are a number of non-destructive techniques available for that purpose such as micro-photoluminescence and photocurrent spectroscopy. [24] Although the testing equipment is available, we have not yet included such measurements into our standard LDA characterization process.

Next, the LDAs undergo aging or accelerated testing in air or in vacuum, depending on the mission requirements, to measure output power degradation rates and verify that they meet the mission lifetime.

The laser diodes, as part of the space laser system, need also to survive mechanical shock and vibration events before and during launch as well as ionizing radiation and temperature extremes during flight. Vibration, shock and temperature extremes can cause mechanical damage to the diode package. Ionizing radiation (gamma, proton) may cause internal damage to the semiconductor resulting in decreased optical efficiency. Durand et al. [25] have reported no apparent changes in LDAs' electro-optical properties under proton irradiation fluences that exceeded the ones experienced at low earth orbit. Our test results have also indicated that the performance of the LDA have not been affected by vibration levels up to 20 grms and total irradiation doses up to $200 \mathrm{krad}$. [26] 
All laser diodes we have tested have survived environmental testing (radiation, vibration, vacuum). The only failures we have experienced were due to Indium solder creeping as seen in the example illustrated in Fig. 12. LDA vendors have recently been using "harder" types of solders with higher melting temperatures such as AuSn and have improved the reliability of their devices.

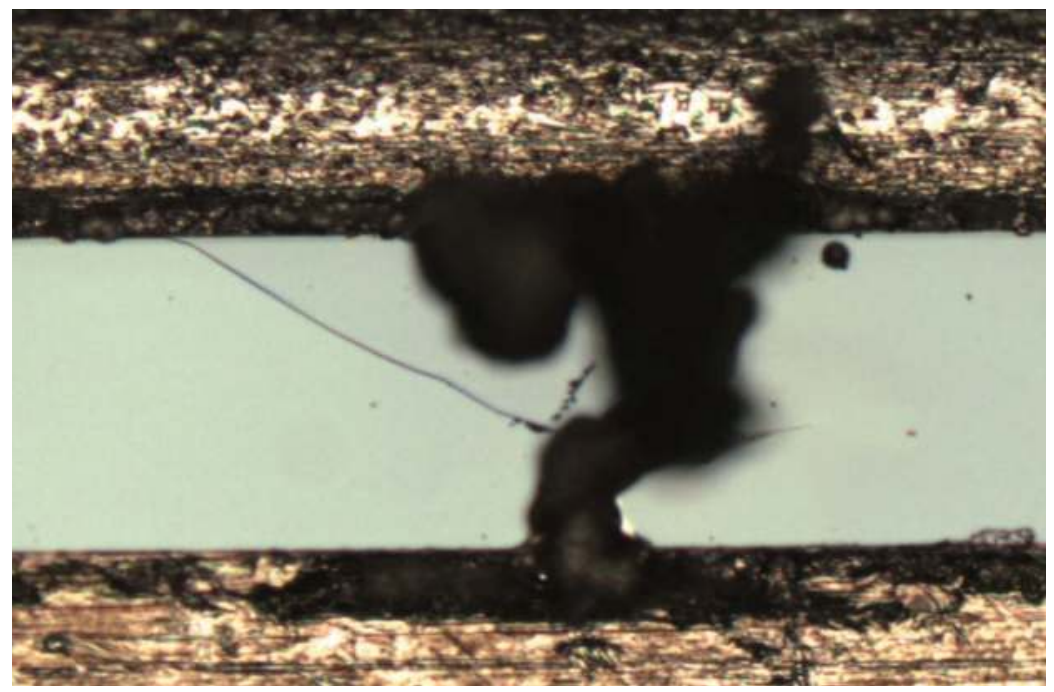

Fig. 12. Image of a diode bar failure due to solder creeping.

\section{Qualification of laser diode arrays for LOLA}

LOLA is one of seven instruments aboard the LRO spacecraft, launched on June 18, 2009.

The mission requirement was for more than one billion shots to be made using a maximum of two flight lasers to complete both the exploration and science phases of the mission. LOLA is the first multi-beam space-based, altimeter system. The transmit beam is split into five using a DOE at the exit aperture of the transmit telescope. Since each laser shot will provide five altimetry time-of-flight measurements, over the course of the mission, LOLA will provide more than five billion measurements. To meet the LOLA goal, we built a total of four lasers - two flight lasers for satellite integration and two engineering model lasers. The lasers are side-pumped Nd:YAG oscillators. Each laser requires two, 2-bar arrays. The total required for the flight build was eight 2-bar arrays (including 2 flight spare lasers.)

The laser design has two 2-bar arrays side-pumping a single Nd:YAG crystal. On orbit, degradation in the diode pumps may be compensated by adjustability in both current amplitude and pulse width. In addition, two lasers are being flown where one might be expected to meet the mission requirements. In this way we have built in both derating and redundancy.

For the EM laser, we bought LDA from two different vendors. The operating conditions and specifications for the LDA are listed in Table 3. 


\begin{tabular}{|c|c|}
\hline Number of bars in array & 2 \\
\hline Power per bar & 70 Watts \\
\hline QCW Peak optical power & 140 Watts \\
\hline Pulse width & $170 \mu \mathrm{s}$ \\
\hline Duty cycle & $0.54 \%$ \\
\hline Center wavelength & $808.0 \mathrm{~nm}$ \\
\hline Center wavelength tolerance & $\pm 2.0 \mathrm{~nm}$ \\
\hline Spectral width & $<3.0 \mathrm{~nm} \mathrm{FWHM}$ \\
\hline Fill factor & $90 \%$ \\
\hline Slow axis divergence & $<12^{\circ}$ \\
\hline Fast axis divergence & $440^{\circ}$ \\
\hline Bar pitch & $100 \mathrm{um} \pm 25 \mathrm{~mm}$ \\
\hline Array size & $<.8 \mathrm{~mm}$ \\
\hline Threshold current & $<25 \mathrm{~A}$ \\
\hline Operating current & $<85 \mathrm{~A}$ \\
\hline Operating voltage & $25^{\circ} \mathrm{C}$ \\
\hline Operating temperature & Vacuum \\
\hline Ambient condition & 1.0 billion pulses \\
\hline Lifetime & .
\end{tabular}

Table 3. Operating conditions and performance specifications of the LOLA laser diode arrays. [27]

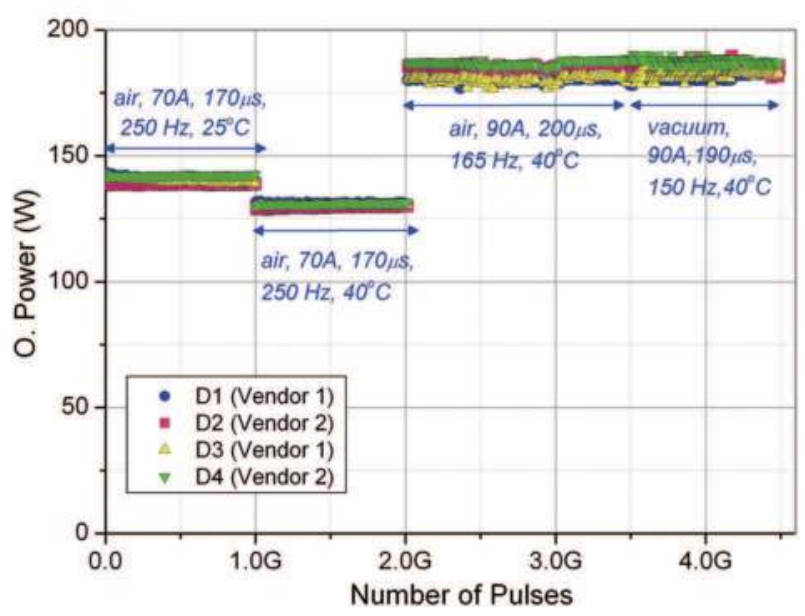

Fig. 13. Test data from LOLA engineering model LDAs operated for 4.5 billion pulses. The power drop at 1 billion pulses was due to the increased operating temperature. [28]

Four EM devices (two per vendor) were tested under various operating conditions, in air and in vacuum, similar to the flight configuration. They were first operated in air, at the beginning-of-life (BOL) operating conditions (70A, $170 \mu \mathrm{s})$ for one billion pulses (Fig. 13). The repetition rate was $250 \mathrm{~Hz}$ instead of $28 \mathrm{~Hz}$ due to test schedule constraints. Then, the operating temperature was increased to $40^{\circ} \mathrm{C}$ for another billion pulses. The LDAs operated 
for another 1.5 billion pulses at 90A, the highest value expected on- orbit, reaching a total of more than 3.5 billion pulses. They were then operated in vacuum for another billion pulses. The LDAs were fully characterized at intervals during this test and all showed less than $5 \%$ total power degradation.

The flight LDA were from a different production run which made this engineering test of no statistical significance to the flight devices. Nevertheless, we found it to be informative, since it gave some indications of the differences between the two different types of LDAs and encouraging since there was not significant power drop even after accumulating 4.5 billion shots.

For the purchase of the flight arrays, a decision was made to buy from and qualify the same two vendors. We purchased 30 LDAs from each vendor. We used 15 arrays for test and qualification and the remaining fifteen as flight devices and flight spares. Because of the extra arrays, it would also be possible to reject units due to poor characteristics. All the arrays were subject to initial characterization and analysis. Two were used for destructive physical analysis to look for latent failure mechanisms. Ten were used for operational testing. The remaining test arrays were reserved as spares to replace failed arrays and maintain statistics.

The LDAs from Vendor 1 (V1) were manufactured using "soft" solder (Indium) while LDAs from Vendor 2 (V2) were made using "hard" solder (AuSn). Both sets of stacks were two-bar assemblies, G-type, with $1 \mathrm{~cm}$ long, $400 \mu \mathrm{m}$ pitch bars. Table 4 summarizes the specifications of the flight LDAs from each vendor.

\begin{tabular}{|l|l|l|}
\hline Property & Vendor 1 & Vendor 2 \\
\hline Type of package & G-type package & G-type package \\
\hline Number of bars & 2 & 2 \\
\hline Bar width & $1 \mathrm{~cm}$ & $1 \mathrm{~cm}$ \\
\hline Number of emitters per bar & 60 & 69 \\
\hline Cavity length & $600 \mu \mathrm{m}$ & $600 \mu \mathrm{m}$ \\
\hline Solder & In & AuSn \\
\hline Type of heatsink & $\begin{array}{l}\text { CuW on both sides of each } \\
\text { bar }\end{array}$ & $\begin{array}{l}\text { CuW on p-side, Au ribbon on } \\
\text { n-side }\end{array}$ \\
\hline Peak Wavelength & $808 \pm 3 \mathrm{~nm}$ at $25^{\circ} \mathrm{C}$ & $808 \pm 3 \mathrm{~nm}$ at $25^{\circ} \mathrm{C}$ \\
\hline $\begin{array}{l}\text { Typical beam divergence } \\
\text { (FWHM) }\end{array}$ & $10 \times 40 \mathrm{deg}$. & $10 \times 40 \mathrm{deg}$. \\
\hline $\begin{array}{l}\text { Peak optical power at } 100 \mathrm{~A}, \\
25^{\circ} \mathrm{C}\end{array}$ & $\geq 200 \mathrm{~W}$ & $\geq 200 \mathrm{~W}$ \\
\hline
\end{tabular}

Table 4. Specifications of the LOLA flight LDAs

All LDAs had been burned-in according to each vendor's factory procedures. As soon as they were received, they were fully characterized and then operated at $100 \mathrm{~A}, 2 \%$ duty cycle until they accumulated another 100 million pulses. They were then re-characterized, ranked and delivered for flight or testing.

Fig. 14 shows an example of a LDA that was rejected for flight based on IR (bottom) and spectrographic NF imaging results (top). The LDA lost $2 \%$ of its power during burn-in and 
then was delivered to be tested in air. It lost another $10 \%$ of its optical power very soon after the beginning of the test.
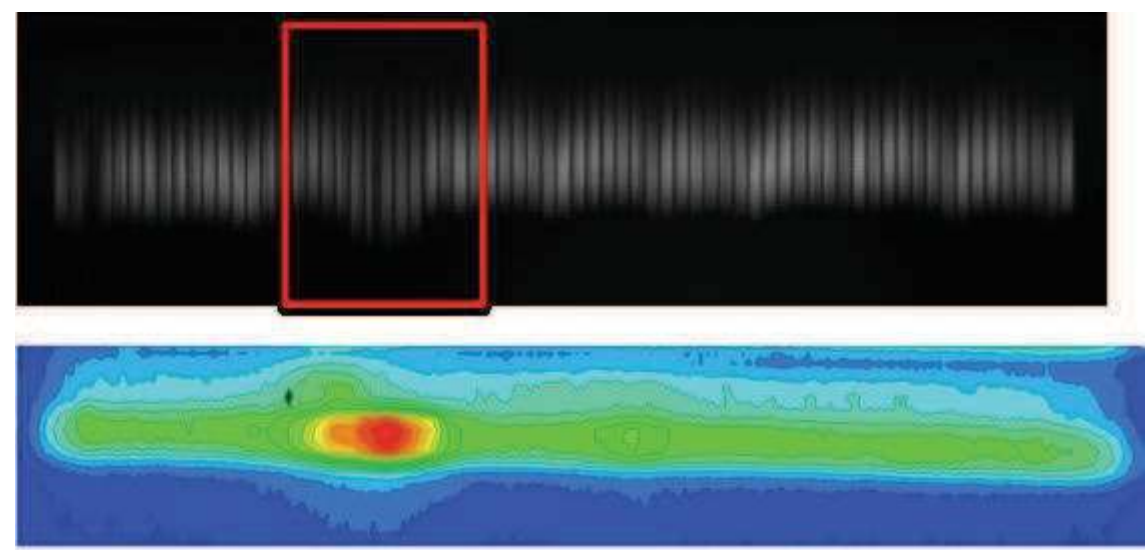

Fig. 14. NF spectrographic image (top) and IR image (bottom) of a LDA from vendor 2 at $100 \mathrm{~A}$ showed an area of thermal stress on one of its bars.

Some LDAs were operated in vacuum and some in air. Table 5 below summarizes all tests performed on the LDAs.

\begin{tabular}{|c|c|c|c|c|c|}
\hline & & & & \multicolumn{2}{|c|}{ Number of LDA } \\
\hline Environment & $\begin{array}{l}\text { Operating } \\
\text { conditions }\end{array}$ & $\begin{array}{c}\text { Peak Power } \\
\text { Rating }\end{array}$ & $\begin{array}{l}\text { Duty } \\
\text { Cycle }\end{array}$ & Vendor \#1 & Vendor \#2 \\
\hline \multirow{2}{*}{ Vacuum } & $28 \mathrm{~Hz}, 70 \mathrm{~A}$ & $70 \%$ & $0.48 \%$ & 3 & 3 \\
\hline & $150 \mathrm{~Hz}, 70 \mathrm{~A}$ & $70 \%$ & $2.55 \%$ & 3 & 3 \\
\hline \multirow{2}{*}{ Air } & $210 \mathrm{~Hz}, 70 \mathrm{~A}$ & $70 \%$ & $3.57 \%$ & 3 & 3 \\
\hline & $155 \mathrm{~Hz}, 100 \mathrm{~A}$ & $100 \%$ & $2.64 \%$ & 3 & 3 \\
\hline
\end{tabular}

Table 5. LOLA performance test matrix. [28]

The purpose of the increased repetition rate was to accelerate the accumulation of pulses. We assumed that as long as the repetition rate is low enough to maintain thermal control, the lifetime of the LDA depends less on operating time and more on the number of accumulated pulses. We tested this assumption by operating a group of LDAs in vacuum at nominal flight conditions and comparing the results to the accelerated vacuum test at $150 \mathrm{~Hz}$. In addition, we operated LDAs in air at their maximum current capacity of $100 \mathrm{~A}$. For all tests the current pulsewidth was set at $170 \mu$ s and the temperature at $25^{\circ} \mathrm{C}$. The vacuum was kept at approximately 1.2E-6 Torr during the course of the tests.

Air and vacuum tests lasted for more than two years and were stopped because of diode driver and other test hardware failures. Except for the group tested in vacuum at $28 \mathrm{~Hz}$, the other three accumulated more than 4.5 billion pulses, far exceeding the mission requirement. All tested LDA were re-characterized after the tests ended. None of the LDAs lost more than $20 \%$ of its power, which would be considered a diode failure. 
In Fig. 15, we have plotted the change in optical power as a function of the pulse count up to $850 \times 10^{6}$ shots, which was the total pulse accumulation of the "slow" group tested in vacuum $(28 \mathrm{~Hz})$. The power drop does not appear to be affected by the repetition rate. The LDAs from Vendor 2 show more power loss than the ones from Vendor 1 as was also the case for the tests in air.

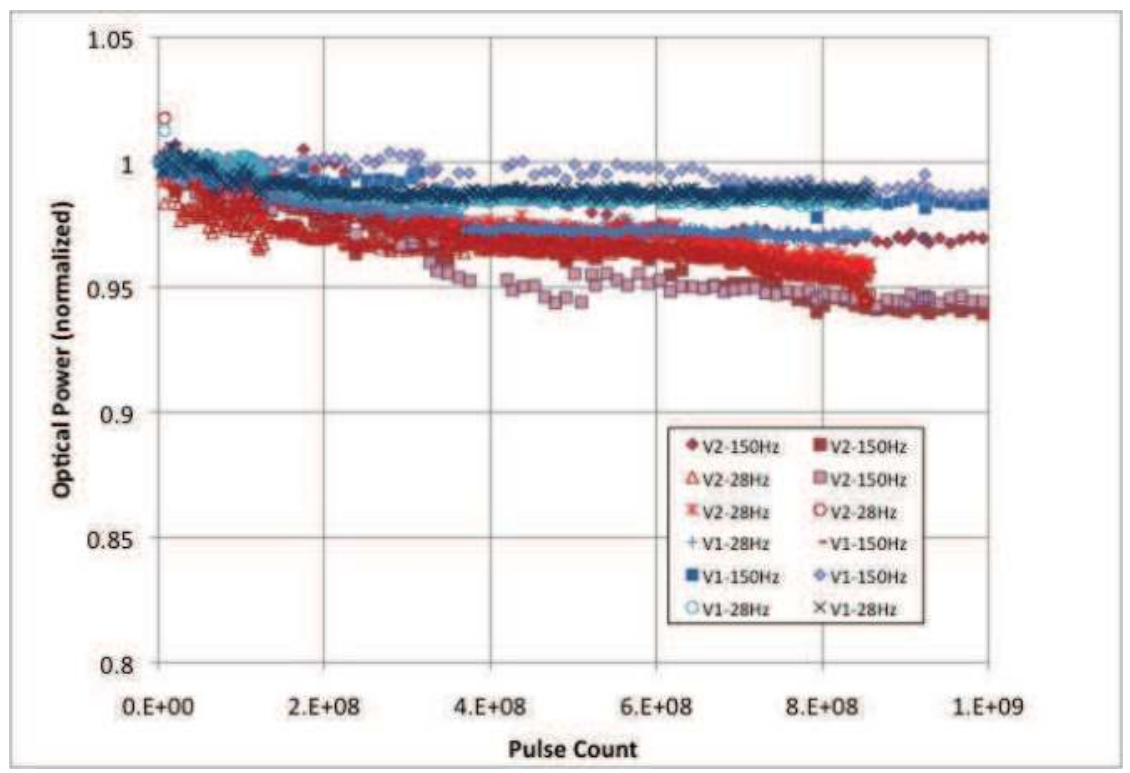

Fig. 15. Optical power vs. pulse count for both groups of LDAs operating in vacuum.

On a parallel effort, two LDAs per vendor were tested during extended testing in vacuum of the LOLA EM laser system. [29] The LOLA EM laser operated in vacuum for over one billion shots. Even though some system degradation was measured during this test it was attributed to other components, not the diode arrays. LDA data helped interpret laser power trends both during the laser EM test and on orbit.

LRO officially reached lunar orbit on June 23, 2009. As of Monday 8/22/2011, LOLA laser 1 (pumped by V1 diode stacks) had accumulated 1,142,583,120 shots and laser 2 (pumped by V2 diode stacks) $656,575,360$ shots totaling $1.799158480 \times 10^{9}$ shots with no significant degradation, well exceeding the mission requirement. Laser degradation curves are in agreement with the diode aging test results and could be included in a future publication by the LOLA team.

\section{ICESat-2 - NASA is transitioning to a new generation of laser remote sensing instruments}

Although successfully used for these spaceflight missions, the current DPSSL technology cannot address all the demanding requirements of future lidar missions. New laser transmitter technologies along with highly efficient measurement approaches are necessary to achieve future lidar remote sensing objectives. 
Due to some of the fundamental issues with designing an efficient, highly reliable, high pulse energy, low repetition rate laser, NASA is moving in the direction of lasers with lower pulse energy and higher repetition rate with a commensurate change in measurement technique and systems engineering. [29]

Thus far all space flight instruments, except for LOLA, are single beam systems. Future space-based instruments will very likely be multiple beam systems that will improve on pointing and reduce the uncertainty in altimetry measurements introduced by the crosstrack surface slope. In addition, for land topography and vegetation, improved pointing will provide observations along exact repeat ground tracks, and sampling along uniformly spaced ground tracks will provide well-sampled grids of topography and biomass. Also to improve on measurement efficiency, a micropulse laser altimetry approach received a lot of interest in the past year. Indeed, ICESat-2, the follow-on mission to ICESat, slated to be launched in 2016, is baselining the micropulse altimetry approach. ICESat-2 will launch a single instrument - the Advanced Technology Laser Altimeter System (ATLAS). In this case, a high repetition rate $(10$ 's $\mathrm{kHz})$, lower energy $(100$ 's $\mu \mathrm{J})$, shorter pulse width $(\sim 1 \mathrm{~ns})$, multi-beam laser altimeter system will be used. A single laser transmitter having sufficient laser energy will be split into multiple beams using DOE similar to the one used on LOLA. [16]

The micropulse laser altimeter system for ATLAS represents a new space-based altimeter architecture for NASA GSFC. Similar altimetry systems utilizing high repetition rate, low energy pulses, multiple wavelengths, multiple beams and single-photon ranging were successfully flown on recent airborne platforms. [30,31,32] All previous laser altimeters for space have been QCW LDA pumped solid-state oscillator/amplifier systems with low repetition rate and high energy with a single-beam footprint (except for LOLA). For ATLAS, continuous wave $(\mathrm{CW})$ diode pumping is anticipated with a short pulse $(<1.5 \mathrm{~ns})$ high repetition rate $(10 \mathrm{kHz})$ laser. The short laser pulse, high beam quality $\left(\mathrm{M}^{2}<1.6\right)$ and narrow, stable linewidth $(<30 \mathrm{pm})$ drive the laser architecture for ATLAS to a MOPA design. The short pulse width and high beam quality can be met with a lower energy, short cavity master oscillator (MO) and a power amplifier (PA) following the $\mathrm{MO}$ can then bring the energy to the required level.

\section{Conclusions}

Diode pumped solid-state laser transmitter technology has come a long way since the first demonstration in 1968. [33] The performance and reliability of semiconductor laser pump diodes have improved many fold since then. Since the successful launch and operation of the MOLA laser, NASA has flown many more successful missions based upon the use of QCW LDA pumped solid-state lasers. Reliability of the QCW LDAs became an issue on ICESat when several of the LDAs failed due to excessive indium solder during the manufacturing process of these arrays resulting in a metallurgical reaction, which progressively eroded the gold conductors through the formation of a non-conducting intermetallic, gold indide, at a rate dependent on temperature. [34] This focused attention on the use of soft solders that can creep and should be used sparingly for high reliability, multi-year applications. It also pointed out the importance of verifying the workmanship of 
the specific devices being used for flight - because the fact that the indium solder was in contact with the gold conductors was the result of a breakdown in process control.

The manufacturing processes of these LDAs are critical to the success of our space program. Our goal is to provide feedback to the vendors based on our assessment of their delivered products. We have developed a set of inspection and characterization processes to inspect, quantify and assess the QCW LDAs for space, which began minimally with the MOLA program and has substantially evolved and improved for several missions in the past ten years. This practice was successfully implemented for two flight missions and we will continue to exercise this procedure with necessary modifications and updates for upcoming programs. The difficulties arose when LDAs from previously qualified vendors underwent changes such as different soldering processes, soldering materials, packaging materials or gain medium, which negate the use of existing data to qualify parts for future programs. These new LDAs will then need to be re-qualified before use. This is a time and cost consuming but necessary and unavoidable step to ensure quality and reliable components on an instrument.

$808 \mathrm{~nm}$ QCW laser pump diodes continue to be a major concern for laser system reliability at NASA. Fortunately, high-reliability, 9xx pump diodes can be used for many NASA systems with appropriate trades. Other NASA laser/lidar systems, however, will require commercial diode arrays at other wavelengths depending on the laser/lidar application (e.g. $792 \mathrm{~nm}$ pumps for $2 \mu \mathrm{m}$ wind lidar). Characterization and lifetime testing of all QCW and $\mathrm{CW}$ diode arrays is critical for future missions.

Future missions such as ICESat-2 will be utilizing CW LDAs for pumping solid state lasers to generate higher repetition rate $(10$ 's $\mathrm{kHz})$, lower energy $\left(\sim 100^{\prime} \mathrm{s} \mu \mathrm{J}\right)$ and shorter pulse width $(<1 \mathrm{~ns})$ pulses. This micropulse lidar or altimetry architecture may represent the next generation of remote sensing instrumentation for NASA. The change provides a higher measurement efficiency and also potentially improves the overall wall-plug efficiency of the laser system used in such instruments. To support this, we are currently developing and modifying our procedures to assess CW packaged free-space laser arrays and fiber coupled single emitters for future space missions.

We have summarized our approach to quantify and qualify LDAs for previous missions. Future missions such as spectroscopy from space by measuring CO2 from Earth's orbit, [35] high resolution mapping of Earth, [36] free-space laser communications [37] and gravitational wave detection [38] will need much improved efficiency and lifetime on pump lasers to ensure successes on missions.

\section{References}

[1] D.E. Smith, M.T. Zuber, and H.V. Frey et al., "Mars orbiter laser altimeter: Experiment summary after the first year of global mapping of Mars," J. Geophys. Res. Planets, vol. 106, no. E10, pp. 23689-23722, Oct. 2001.

[2] H.J. Zwally, B. Schutz, W. Abdalati et al., "ICESat's laser measurements of polar ice, atmosphere, ocean, and land," J. Geodyn., vol. 34, pp. 405- 445, 2002. 
[3] D.M. Winker, J. Pelon, and M.P. McCormick, “The CALIPSO mission: Spaceborne lidar for observation of aerosols and clouds," Proc. SPIE, 4893, 1-11, 2003.

[4] J.F. Cavanaugh, et al., "The Mercury Laser Altimeter Instrument for the MESSENGER Mission," Space Sci Rev (2007) 131: 451-479, DOI 10.1007/s11214-007-9273-4.

[5] D.E. Smith, "The Lunar Orbiter Laser Altimeter Investigation on the Lunar Reconnaissance Orbiter Mission," Space Sci Rev (2010) 150: 209-241, DOI 10.1007/s11214-009-9512-y.

[6] R.S. Afzal, "Mars Observer Laser Altimeter: laser transmitter," Appl. Opt. 33, 3184-3188 (1994).

[7] R.S. Afzal, et al., "The Geoscience Laser Altimeter System (GLAS) Laser Transmitter," Selected Topics in Quantum Electronics, IEEE Journal of, 13, 511-536, (2007).

[8] F. Hovis, "Qualification of the Laser Transmitter for the CALIPSO Aerosol Lidar Mission", in Proc. of SPIE, 6100, 61001X (2006).

[9] D.J. Krebs, et al., "Compact, passively Q-switched Nd:YAG laser for the MESSENGER mission to Mercury," Appl. Opt. 44, 1715-1718 (2005).

[10] A.W. Yu, et al., "Laser Transmitter for the Lunar Orbit Laser Altimeter (LOLA) Instrument," in Conference on Lasers and Electro-Optics/Quantum Electronics and Laser Science Conference and Photonic Applications Systems Technologies, paper CMQ2, (2008).

[11] D.E. Smith, et al., "Mars Orbiter Laser Altimeter: Experiment summary after the first year of global mapping of Mars," J. Geophys. Res., 106, (E10), 23, 689-23,722 (2001).

[12] J.L. Bufton, "Shuttle Laser Altimeter," Lasers and Electro-Optics, 1997. CLEO/Pacific Rim '97., 143-144, (1997); J. Garvin, et al., “Observations of the Earth's topography from the Shuttle Laser Altimeter (SLA): laser-pulse echo-recovery measurements of terrestrial surfaces", Phys. Chem. of the Earth, 23, 1053-1068 (1998).

[13] A compilation of the recent scientific results can be found in a special issue on ICESat-I in Geophysical Research Letters, 32, Numbers 21, 22, and 23, (2005).

[14] W.L. Sjogrem, Apollo Laser Altimeter Analysis, Final Report, NASA JPL, (1975).

[15] J.G. Smith, et al., "Diffractive Optics for Moon Topography Mapping," Proc. SPIE, 6223, (2006).

[16] M. Fukuda, Reliability and Degradation of Semiconductor Lasers and LEDs, Artech House, Boston, 1991.

[17] A. Kozlowska, "Infrared imaging of semiconductor lasers", Semicond. Sci. Technol. 22 R27 2007.

[18] P.G. Eliseev, N.B. Sverdlov and N. Shokhudzhaev, "Reduction of the threshold current of InGaAsP InP heterolasers by unidirectional compression," Sov. J. Quantum Electron. 14, 1120-1121, 1984.

[19] N.B. Patel, J. E. Ripper, and P. Brosson, "Behavior of threshold current and polarization of stimulated emission of GaAs injection lasers under uniaxial stress," IEEE J. Quantum Electron. QE-9, 338-341, 1973. 
[20] D. Lisak, T.D. Cassidy and A.H. Moore, “Bonding stress and reliability of high power GaAs based lasers," IEEE Trans. Components Packag. Manuf. Technol. Part A 24, 92-98, 2001.

[21] F.M. Ryan and R.C. Miller, "The effect of uniaxial strain on the threshold current and output of GaAs lasers," Appl. Phys. Lett. 3, 162-163, 1963.

[22] M.A. Stephen, A. Vasilyev, E. Troupaki, G.R. Allan, and N.B. Kashem, "Characterization of high-power quasi-cw laser diode arrays", Proc. SPIE 5887, 58870A1 (2005).

[23] M. Voss, C. Lier, U. Menzel, A. Barwolff and T. Elsaesser, "Time-resolved emission studies of GaAs/AlGaAs laser diode arrays on different heat sinks", J.Appl. Phys. 79(2), pp 1170-1172, 1996.

[24] J. Tomm, J. Jimenez, "Quantum-Well Laser Array Packaging", McGraw-Hill Professional, New York, 2006.

[25] Y. Durand, A. Culoma, R. Meynart, J. Pinsard J., and G. Volluet, "Performance of high-power laser diode arrays for spaceborne lasers," Appl. Opt. 45, 5752-5757 (2006).

[26] E. Troupaki, A. Vasilyev, N.B. Kashem, G.R. Allan, and M.A. Stephen, "Space qualification and environmental testing of quasi-continuous wave laser diode arrays", J.Appl. Phys., Vol. 100, pp. 063109 (2006).

[27] E. Troupaki, A. Vasilyev, M.A. Stephen, A.A. Seas and N.B. Kashem, "Qualification of laser diode arrays for space applications", Proc. SPIE 7193, 719307 (2009).

[28] G.B. Shaw, M.A. Stephen, E. Troupaki, A.A. Vasilyev and A.W. Yu, "Longevity validation of the LOLA laser design by extended vacuum testing of the LOLA engineering model laser", Proc. SPIE 7193, 719306 (2009).

[29] A.W. Yu, M.A. Stephen, S. X. Li, G.B. Shaw, A. Seas, E. Dowdye, E. Troupaki, P. Liiva, D. Poulios, and K. Mascetti, "Space laser transmitter development for ICESat-2 mission", Proc. SPIE 7578, 757809 (2010).

[30] D.J. Harding, "The Swath Imaging Multi-polarization Photon-counting Lidar (SIMPL): A Spaceflight Prototype," Proceedings of the 2008 IEEE International Geoscience \& Remote Sensing Symposium, 06-11 March, Boston, MA, (2008).

[31] P. Dabney, et al., "The Slope Imaging Multi-Polarization Photon Counting Lidar: Development and Performance Results," Paper 4644, Proc. IEEE Int. Geosci. Rem. Sens. Symp., Honolulu, HI, 25-30 July 2010.

[32] J. Degnan, et al., "Photon-counting, 3D imaging lidars operating at megapixels per second," CLEO/QELS 2009. 2-4 June 2009, Baltimore, MD.

[33] M. Ross, "YAG laser operation by semiconductor laser pumping," Proc. IEEE. vol. 56, pp. 196-197. 1968

[34] R.A. Kichak, IGARB Executive Summary, http://icesat.gsfc.nasa.gov/publications.htm.

[35] J.B. Abshire, H. Riris, G.R. Allan, C.J. Weaver, J. Mao, X. Sun, W.E. Hasselbrack, A.W. $\mathrm{Yu}$, A. Amediek, Y. Choi and E.V. Browell, "A lidar approach to measure $\mathrm{CO}_{2}$ concentrations from space for the ASCENDS Mission", Proc. SPIE 7832, 78320D (2010); doi:10.1117/12.868567. 
[36] A.W. Yu, M.A. Krainak, D.J. Harding, J.B. Abshire, X. Sun, S. Valett, J. Cavanaugh, and L. Ramos-Izquierdo, "Spaceborne laser instruments for high-resolution mapping," Proc. SPIE 7578, 757802 (2010), DOI:10.1117/12.843191.

[37] LCRD - Laser Communications Relay Demonstration Mission, http://www.nasa.gov/offices/oct/crosscutting_capability/tech_demo_missions.h tml.

[38] LISA - Laser Interferometer Space Antenna, http:/ /lisa.nasa.gov/ 


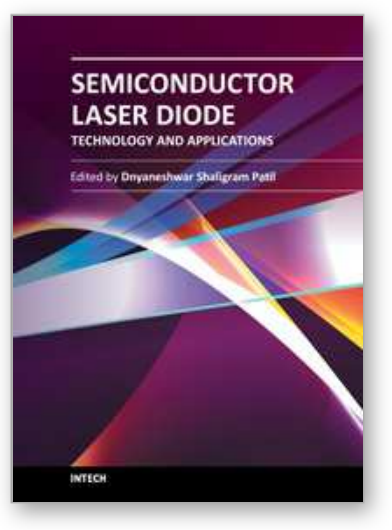

\author{
Semiconductor Laser Diode Technology and Applications \\ Edited by Dr. Dnyaneshwar Shaligram Patil
}

ISBN 978-953-51-0549-7

Hard cover, 376 pages

Publisher InTech

Published online 25, April, 2012

Published in print edition April, 2012

This book represents a unique collection of the latest developments in the rapidly developing world of semiconductor laser diode technology and applications. An international group of distinguished contributors have covered particular aspects and the book includes optimization of semiconductor laser diode parameters for fascinating applications. This collection of chapters will be of considerable interest to engineers, scientists, technologists and physicists working in research and development in the field of semiconductor laser diode, as well as to young researchers who are at the beginning of their career.

\title{
How to reference
}

In order to correctly reference this scholarly work, feel free to copy and paste the following:

Elisavet Troupaki, Mark A. Stephen, Aleksey A. Vasilyev and Anthony W. Yu (2012). Laser Diode Pump Technology for Space Applications, Semiconductor Laser Diode Technology and Applications, Dr. Dnyaneshwar Shaligram Patil (Ed.), ISBN: 978-953-51-0549-7, InTech, Available from: http://www.intechopen.com/books/semiconductor-laser-diode-technology-and-applications/laser-diode-pumptechnology-for-space-applications

\section{INTECH}

open science | open minds

\section{InTech Europe}

University Campus STeP Ri

Slavka Krautzeka 83/A

51000 Rijeka, Croatia

Phone: +385 (51) 770447

Fax: +385 (51) 686166

www.intechopen.com

\section{InTech China}

Unit 405, Office Block, Hotel Equatorial Shanghai

No.65, Yan An Road (West), Shanghai, 200040, China 中国上海市延安西路65号上海国际贵都大饭店办公楼 405 单元

Phone: +86-21-62489820

Fax: $+86-21-62489821$ 
(C) 2012 The Author(s). Licensee IntechOpen. This is an open access article distributed under the terms of the Creative Commons Attribution 3.0 License, which permits unrestricted use, distribution, and reproduction in any medium, provided the original work is properly cited. 